\title{
Assessment of the implementation and the achievements of the 3D approach within Senegal's National Family Planning Action Plan (NFPAP)
}

Fatou Mbow

Population Council

Nafissatou Diop

Population Council

Follow this and additional works at: https://knowledgecommons.popcouncil.org/departments_sbsr-rh

Part of the Demography, Population, and Ecology Commons, Family, Life Course, and Society Commons, and the International Public Health Commons How does access to this work benefit you? Let us know!

\section{Recommended Citation}

Mbow, Fatou and Nafissatou Diop. 2017. "Assessment of the implementation and the achievements of the 3D approach within Senegal's National Family Planning Action Plan (NFPAP)," Technical brief. Dakar: Population Council, The Evidence Project. 

A leader in the field of family planning (FP) in West Africa, Senegal has undertaken diverse initiatives to reach its FP goals, including the development of the 2012-2015 National Family Planning Action Plan (NFPAP).

The NFPAP is based on the 3D approach (Democratization, Demedicalization, Decentralization). With the NFPAP almost at the end of its term and at a time when the development of a new plan is being considered, it is important to document the 3D approach, its implementation and its achievements. The Population Council conducted this study with the Directorate of Reproductive Health and Child Survival (DRHCS) of the Ministry of Health and Social Action (MHSA), the United States Agency for International Development (USAID) and the Coordinating Unit of the Ouagadougou Partnership. The study was conducted as part of the Evidence Project, supported by USAID.

\section{The $2012-2015$ NFPAP anticipated}

\section{0,000 new users of modern}

\section{contraceptive methods, including 125,000} obtaining an FP method from the public sector, 100,000 from the private sector, and 125,000 at the community level.

The goals of the study were: to document the 3D approach in relation to the NFPAP; describe lessons learned from the approach's implementation; and widely share the good practices identified. The study sought to generate evidence to inform decision-making, particularly for the development of the next NFPAP.

\section{METHODOLOGY}

The study combined a literature review and qualitative research in the Dakar and Thiès regions, including 26 in-depth interviews (IDIs) with FP stakeholders and eight focus group discussions (FGDs) with women of reproductive age $(25-44)$ who were current or recent (within the last five years) FP users.

\section{RESULTS}

Knowledge of the 3D approach: Only 1/5 of FP stakeholders knew of the 3D approach, while none of the women had heard of it.

Knowledge of actions undertaken in the framework of each "D": Many respondents could cite actions undertaken as part of each "D," once they were given the definition.

- Democratization: Primary actions were: those at political, legal and regulatory levels; for communication; those affecting costs; those for the development of leadership and empowerment of women; those for young people; or those related to public-private partnerships.

- Demedicalization: Actions were related to task shifting and to the development of community-based FP.

- Decentralization: Actions were mainly related to service provision, decision-making, training for health care providers and information of the population; implementation of the Informed Push Model (IMP) for products security; and the SAFI (i.e. itinerant midwives) strategy. The involvement of local authorities in construction of health facilities, FP financing and recruitment of qualified personnel was also noted.

Achievements of each "D": The following achievements were cited:

- Democratization: The involvement of other sectors and stakeholders allowed, in particular, for the improvement of knowledge and perceptions of FP, harmonization of contraceptive prices, expansion of service provision, and increased female leadership.

- Demedicalization: Task shifting and community-based distribution led to broadening the skills of community health workers (CHW) and bringing services closer to the population.

- Decentralization: Ownership and accountability at all levels led to better availability of and access to a larger range of modern FP methods, including in the most remote areas, increased number of service delivery points (SDPs), and introduction of long-acting contraceptives at health posts.

66

"Ultimately, the 3D approach, it is something we do every day without even knowing it. So, this study is really a good initiative. It [the approach] just needs to be popularized so that interventions are better structured and stakeholders can put a framework around what they do."

- FP stakeholder, Thiès

Overview of the 3D approach: Participants disagreed somewhat on which "D" contributed most to progress between 2012 and 2015, but agreed that the "Ds" are complementary 
and interdependent. The 3D approach was perceived as a good one, especially due to its multi-sectoral nature. Respondents described it as innovative and felt it should be systematized and popularized for proper ownership by stakeholders. FP actors suggested that it should guide the next NFPAP.

Perceived effects of the 3D approach: The main perceived effects were: better geographic and financial access to FP services, increased contraceptive prevalence rate, capacity building of community actors, increased approval of FP, product availability, improved FP knowledge, birth spacing, and reduced maternal and child mortality.

\section{(6)}

"Over these 5 years, we see that FP is much more decentralized, half the population felt the impact of FP and that was not the case before because there were places where FP did not exist. But over these 5 years, everyone has access to it." - FGD, Mbour

Sustainability of the 3D approach: Sustainability will require widespread awareness about the approach, better involvement and ownership by stakeholders, implementation of strategies for FP commodities security, and motivation and continued training for CHWs.

\section{DISCUSSION}

The 3D approach is not a well-known concept among FP stakeholders, even though many apply it in their daily activities. Institutional, political and organizational changes made indicate willingness on the part of the highest authorities to promote FP and reduce unmet need, and point to strong promises for achieving Senegal's development goals. However, its inclusion in the next NFPAP requires addressing some challenges:

\section{Democratization:}

- Implementing initiatives for free services creates challenges for health facilities, which have to recover costs;

- Legal and regulatory provisions that constitute barriers to private sector involvement should be revised to open opportunities for service expansion. However, to guarantee market stability and equitable access, the issue of subsiding products or not for the for-profit private sector must be addressed.
- Although there is a strategic plan for the reproductive health of adolescents and young people, FP for single people is not expressly taken into account. Therefore, it is critical to implement interventions for all young people.

- Unmet need remains high and FP actors are called upon to implement measures to ensure FP users' access to and voluntary continuation of the program.

- The contribution of each sector must be integrated so that multi-sectorality is a reality, not just a slogan.

- Strong involvement of the private sector in FP service provision presents real opportunities to broaden access to services and boost the contraceptive prevalence rate.

\section{Strong involvement of the private} sector in FP service provision presents real opportunities to broaden access to services and boost the contraceptive prevalence rate.

\section{Demedicalization:}

- The integration of health huts in the health pyramid appears to be a priority in a context in which community staff motivation issues are acute.

- Furthermore, despite progress made in the use of CHWs for service provision, their credibility is not guaranteed either with FP stakeholders or with female FP users. Efforts must be intensified to ensure the quality of the services they provide, in order not to lose gains. This ranges from training to monitoring and supervision to motivation.

- Legal and regulatory frameworks must be strengthened for the supervised involvement of CHWs.

\section{Decentralization:}

- The lack of health infrastructure and qualified staff require the development of alternatives, such as improved health huts, to advance decentralization.

- In terms of sustainability, neither financing of the FP program nor availability of products can be indefinitely carried by financial and technical partners.

- Beyond the demonstrated political will and the existence of a dedicated budget line, the actual and significant strengthening of financial resources would contribute to greater government support. 


\section{RECOMMANDATIONS}

For the State/MHSA:

- Increase the number of health facilities and bring them as close to the people as possible.

- Increase the dedicated FP budget line.

- Review the legal and regulatory frameworks that hinder service provision by the private sector and by CHWs.

- Implement mechanisms to motivate community-level workers.

- Effectively implement the multi-sectoral dimension of FP service provision.

- Popularize the 3D approach for better ownership and application.

- Clearly specify how the 3D approach will be articulated in the next NFPAP.

For FP stakeholders and technical partners:

- Assume more ownership of the 3D approach and incorporate it into interventions.

- Reinforce training support for health professionals as well as community-level agents.
- Strengthen advocacy for increased FP financing by the state and local authorities.

- Assess and document good practices, including the cost component, to allow for replication, scaling up and sharing when applicable.

For financial partners:

- Ensure the availability of products.

- Support the implementation of FP research programs and interventions that will contribute to the achievement of development goals in Senegal and globally, such as the Sustainable Development Goals.

\section{CONCLUSION}

The 3D approach provides an innovative framework for structuring FP interventions. Achievements related to the approach have contributed to the improvement of FP indicators. Inclusion of the approach and its articulation from the very beginning of the development of the next NFPAP are essential to more quickly boost FP in order to improve the health of the population and to reduce maternal, newborn and child mortality.

\section{THE EVIDENCE PROJECT}

Population Council Sacré Cœur Pyrotechnie Appartement 2ème Etage à Droite

Dakar

Sénégal

21027 Dakar Ponty

tél: +221.33.859.5300

evidenceproject@popcouncil.org
The Evidence Project is made possible by the generous support of the American people through the United States Agency for International Development (USAID) under the terms of cooperative agreement no. AID-OAA-A-13-00087. The contents of this document are the sole responsibility of the Evidence Project and Population Council and do not necessarily reflect the views of USAID or the United States Government.

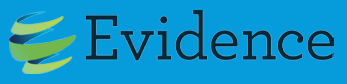

The Evidence Project uses implementation science--the strategic generation, translation, and use of evidence-to strengthen and scale up family planning and reproductive health programs to reduce unintended pregnancies worldwide. The Evidence Project is led by the Population Council in partnership with INDEPTH Network, International Planned Parenthood Federation, PATH, Population Reference Bureau, and a University Research Network.

Suggested Citation: Mbow FB \& Diop N. 2017. "Assessment of the implementation and the achievements of the 3D approach within Senegal's National Family Planning Action Plan (NFPAP)”, Technical Brief. Dakar, Senegal: Population Council, The Evidence Project.

@ 2017 The Population Council, Inc.

Photo credit on cover page @ 2011 Adrienne Allison World Vision, Courtesy of Photoshare

For more information, contact Nafissatou Diop at ndiop@popcouncil.org 